\title{
Pre-existing diabetes, maternal glycated haemoglobin, and the risks of fetal and infant death: a population-based study
}

\author{
Peter W. G. Tennant • Svetlana V. Glinianaia • \\ Rudy W. Bilous • Judith Rankin • Ruth Bell
}

Received: 2 August 2013 / Accepted: 28 October 2013 /Published online: 29 November 2013

(C) Springer-Verlag Berlin Heidelberg 2013

\begin{abstract}
Aims/hypothesis Pre-existing diabetes is associated with an increased risk of stillbirth, but few studies have excluded the effect of congenital anomalies. This study used data from a long-standing population-based survey of women with preexisting diabetes to investigate the risks of fetal and infant death and quantify the contribution of glycaemic control.

Methods All normally formed singleton offspring of women with pre-existing diabetes (1,206 with type 1 diabetes and 342 with type 2 diabetes) in the North of England during 19962008 were identified from the Northern Diabetes in Pregnancy Survey. RRs of fetal death ( $\geq 20$ weeks of gestation) and infant death were estimated by comparison with population data from the Northern Perinatal Morbidity and Mortality Survey. Predictors of fetal and infant death in women with pre-existing diabetes were examined by logistic regression.

Results The prevalence of fetal death in women with diabetes was over four times greater than in those without (RR 4.56 [95\% CI 3.42, 6.07], $p<0.0001)$, and for infant death it was
\end{abstract}

Electronic supplementary material The online version of this article (doi:10.1007/s00125-013-3108-5) contains peer-reviewed but unedited supplementary material, which is available to authorised users.

P. W. G. Tennant $(\bowtie) \cdot$ S. V. Glinianaia $\cdot$ J. Rankin $\cdot$ R. Bell Institute of Health \& Society, Newcastle University, Baddiley-Clark Building, Richardson Road, Newcastle upon Tyne NE2 4AX, UK e-mail: peter.tennant@ncl.ac.uk

R. W. Bilous

Institute of Cellular Medicine, Newcastle University,

Newcastle upon Tyne, UK

R. W. Bilous

James Cook University Hospital, South Tees NHS Trust,

Middlesbrough, UK

J. Rankin $\cdot$ R. Bell

Regional Maternity Survey Office, Public Health England,

Newcastle upon Tyne, UK nearly doubled (RR 1.86 [95\% CI 1.00, 3.46], $p=0.046$ ). There was no difference in the prevalence of fetal death ( $p=0.51)$ or infant death $(p=0.70)$ between women with type 1 diabetes and women with type 2 diabetes. There was no evidence that the RR of fetal and infant death had changed over time $(p=0.95)$. Increasing periconception $\mathrm{HbA}_{1 \mathrm{c}}$ concentration above $49 \mathrm{mmol} / \mathrm{mol}$ (6.6\%) (adjusted odds ratio [aOR] 1.02 [95\% CI 1.00, 1.04], $p=0.01$ ), prepregnancy retinopathy (aOR $2.05[95 \% \mathrm{CI}$ $1.04,4.05], p=0.04)$ and lack of prepregnancy folic acid consumption (aOR 2.52 [95\% CI 1.12, 5.65], $p=0.03$ ) were all independently associated with increased odds of fetal and infant death.

Conclusions/interpretation Pre-existing diabetes is associated with a substantially increased risk of fetal and infant death in normally formed offspring, the effect of which is largely moderated by glycaemic control.

Keywords Diabetes mellitus $\cdot \mathrm{HbA}_{1 \mathrm{c}} \cdot$ Miscarriage $\cdot$ Neonatal death $\cdot$ Pregnancy $\cdot$ Stillbirth

$\begin{array}{ll}\text { Abbreviations } \\ \text { aOR } & \text { Adjusted odds ratio } \\ \text { IQR } & \text { Interquartile range } \\ \text { LOWESS } & \text { Locally weighted scatterplot smoothing } \\ \text { NICE } & \text { National Institute for Health and Care Excellence } \\ \text { NorCAS } & \text { Northern Congenital Abnormality Survey } \\ \text { NorDIP } & \text { Northern Diabetes in Pregnancy Survey } \\ \text { PMMS } & \text { Perinatal Morbidity and Mortality Survey }\end{array}$

Introduction

Diabetes is one of the most common pre-existing maternal conditions complicating pregnancy. Affecting $0.5 \%-2 \%$ of 
pregnancies, the prevalence is rising as a consequence of the obesity epidemic and increases in maternal age. This has considerable implications, since pre-existing diabetes (both type 1 and type 2) is associated with a range of pregnancy complications, including increased risks of macrosomia, congenital anomaly and delivery by Caesarean section [1-3]. It has long been observed that pre-existing diabetes is also associated with an increased risk of stillbirth [4], although there is heterogeneity in the estimated RR [5].

Prepregnancy care, particularly focusing on optimising glycaemic control, improves birth outcomes in women with pre-existing diabetes [6]. With intensive support, some women with diabetes can achieve similar outcomes to those without [7], an unmet goal of the St Vincent Declaration [8]. It is uncertain, however, whether such improvements can be achieved in routine clinical care. Observational studies from the last 20 years have not shown any reduction in the RR of fetal death [9-18], despite guidelines advising women with pre-existing diabetes to achieve good glycaemic control before pregnancy $[19,20]$.

There is a paucity of data on the risks of fetal and infant death independent of congenital anomaly, and the contribution of glucose control and other clinical and sociodemographic factors are poorly described. We used unique data from several long-standing population-based registers in the North of England to investigate the association between pre-existing diabetes and the risks of fetal and infant death in normally formed offspring, and to quantify the contribution of glycaemic control.

\section{Methods}

The Northern Diabetes in Pregnancy Survey (NorDIP) The North of England (UK) is a geographically distinct area with a population of three million and approximately 32,000 births per year (see electronic supplementary material [ESM] Fig. 1). The NorDIP records details of all pregnancies in women resident in the region and diagnosed with (type 1 or type 2) diabetes at least 6 months before conception. Pregnancies in women with gestational diabetes (i.e. hyperglycaemia first diagnosed during pregnancy) are not included. Clinicians working in the region's nine units collect and supply information on a range of clinical and sociodemographic variables, including maternal $\mathrm{HbA}_{1 \mathrm{c}}$ concentration before conception, in the first trimester and in the third trimester. For further details, see Glinianaia et al [1].

Study sample This study includes data on all singleton pregnancies in women with pre-existing diabetes delivered at or after 20 completed weeks of gestation between 1 January 1996 and 31 December 2008. Pregnancies complicated by major congenital anomalies, which have previously been shown to be associated with both preexisting diabetes and the risk of fetal and infant death $[2,21]$, were identified from the Northern Congenital Abnormality Survey (NorCAS) and excluded. The NorCAS is a long-standing population-based register of congenital anomaly that collects data on all cases of congenital anomaly occurring in all deliveries in the North of England, irrespective of maternal diabetes status (for further details, see Bell et al [2]). The total number of singleton live births and fetal and infant deaths were obtained from the UK Office for National Statistics (www.statistics.gov.uk) and the Northern Perinatal Morbidity and Mortality Survey (PMMS) [22], respectively. The number of normally formed offspring was determined by subtracting the number of NorCAS registrations.

Definitions 'Late miscarriages' are the spontaneous loss of a fetus at 20-23 completed weeks of gestation. 'Stillbirths' are deliveries of a fetus showing no signs of life at 24 or more completed weeks of gestation. 'Late stillbirths' are stillbirths at 28 or more completed weeks of gestation. 'Antepartum stillbirths' are stillbirths where the fetus died before the onset of labour. 'Intrapartum stillbirths' are stillbirths where the fetus died after the onset of labour. 'Fetal deaths' comprise late miscarriages and stillbirths. 'Neonatal deaths' are deaths, after live birth, within the first 28 days of life. 'Postneonatal deaths' are deaths, after live birth, of an infant aged 28 days or more, but less than 1 year. 'Infant deaths' comprise neonatal deaths and postneonatal deaths.

Analysis Prevalence rates were estimated per 1,000 births and late miscarriages for fetal outcomes, and per 1,000 live births for infant outcomes. The Clopper-Pearson (exact) method was used to estimate $95 \%$ CIs for prevalences. RRs were calculated by comparing the prevalences in women with preexisting diabetes with the prevalence in the remaining population. To examine whether the RR for fetal and infant death had changed over time, a cross-product interaction between diabetes status and year of delivery was evaluated in a Poisson regression model. RRs for fetal death at specific gestational ages were estimated using the 'fetuses-at-risk' approach [23]. In each period, the proportion of cases from the total number of ongoing pregnancies (i.e. containing fetuses 'at risk of fetal death') was compared. The number of ongoing pregnancies at each gestational age was estimated from a reference UK population [24].

ORs and 95\% CIs for all variables with hypothesised influences on fetal and/or infant death were analysed in relation to fetal death, late stillbirth, infant death, fetal and infant death combined, and late stillbirth and infant death combined within a series of logit-linked generalised estimating equations. Between-mother variation was modelled as a random intercept to account for the non-independence of repeat pregnancies in the same woman. Periconception $\mathrm{HbA}_{1 \mathrm{c}}$ was 
defined as the closest measurement within 3 months before the last menstrual period (available for $48.8 \%$ of pregnancies) or mean first-trimester measurement ( $<14$ weeks of gestation) (available for $86.0 \%$ of pregnancies) for women with no preconception measurement. Periconception $\mathrm{HbA}_{1 \mathrm{c}}$ concentration was chosen as a reasonable surrogate of preconception $\mathrm{HbA}_{1 \mathrm{c}}$ concentration, as first-trimester $\mathrm{HbA}_{1 \mathrm{c}}$ correlated highly with preconception $\mathrm{HbA}_{1 \mathrm{c}}$ (Spearman's correlation coefficient 0.76). Third-trimester $\mathrm{HbA}_{1 \mathrm{c}}$ was examined only in relation to deliveries at $\geq 28$ weeks of gestation. Adjusted ORs (aORs) were estimated using a backwards stepwise approach; all variables were entered into the model, and non-significant ones were removed iteratively, by descending $p$ value, until only those with $p<0.1$ remained. Cross-product interaction terms were used to explore whether the effect of each variable with a significant independent association on the risk of fetal and infant death varied by diabetes type. The relationships of periconception and third-trimester $\mathrm{HbA}_{1 \mathrm{c}}$ concentration with the risks of fetal and infant death were explored by locally weighted scatterplot smoothing (LOWESS) [25]. LOWESS produces smoothed estimates of the association between two variables without requiring a priori specification. Since Jshaped associations were observed between both variables and the risk of fetal death, all models of fetal death or fetal and infant death combined were modelled by piecewise linear regression with knots at the lowest LOWESS values (49 $\mathrm{mmol} / \mathrm{mol}\left[6.6 \%\right.$ ] for periconception $\mathrm{HbA}_{1 \mathrm{c}}$ and $43 \mathrm{mmol} / \mathrm{mol}\left[6.1 \%\right.$ ] for third-trimester $\mathrm{HbA}_{1 \mathrm{c}}$ ). LOWESS was also used to estimate the absolute risks of fetal death, stillbirth, late stillbirth and infant death for selected categories of periconception and third-trimester $\mathrm{HbA}_{1 \mathrm{c}}$ by averaging the modelled risk for all values within that category (with CIs being estimated by bootstrapping from 10,000 subsamples). Logit-linked generalised estimating equations were used to estimate the absolute risk of late stillbirth for selected categories of periconception and third-trimester $\mathrm{HbA}_{1 \mathrm{c}}$ simultaneously by evaluating the model at the category-specific means (with CIs being estimated using the delta method [26]). Owing to instability at the LOWESS tails, only categories within the 5th and 95th centile of case values are reported. Participants with missing data were excluded from individual analyses by casewise deletion. Analyses were performed using Stata version 11.1 (Statacorp, College Station, TX, USA). $p<0.05$ was considered statistically significant.

Ethics approval and research governance Newcastle Research Ethics Committee originally granted approval for the NorDIP in 1993. Data are now obtained and held with informed consent.

Role of the funding source The funders had no role in the study design, data collection and analysis, decision to publish, or preparation of the manuscript. The views expressed in this manuscript are entirely those of the authors and do not necessarily reflect those of the funders.

\section{Results}

Figure 1 shows the derivation of the study sample. Overall, 397,392 singleton live births, stillbirths and late miscarriages uncomplicated by major congenital anomalies were identified during the study period, including 1,548 in women

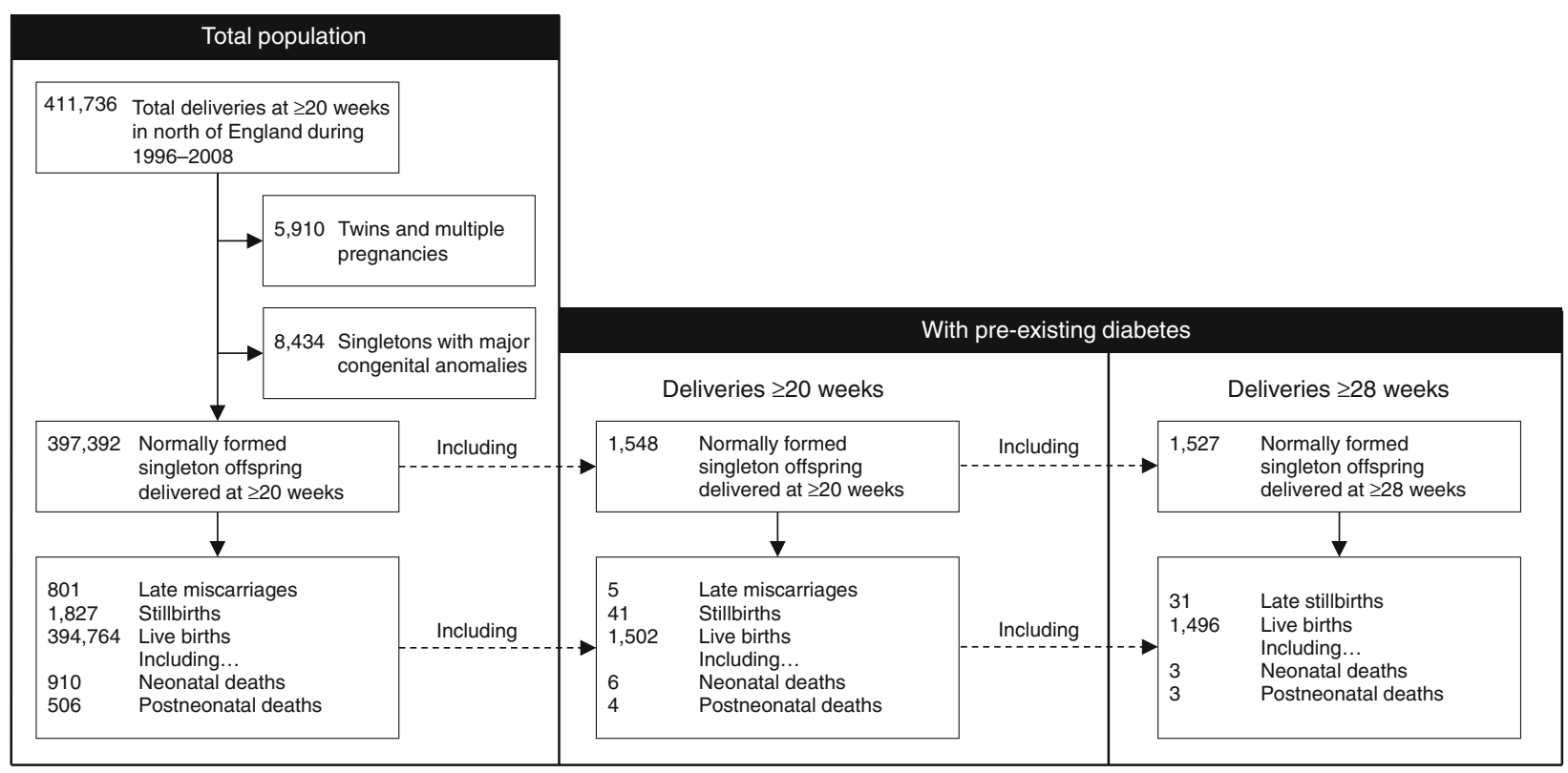

Fig. 1 Derivation of the study sample 
with pre-existing diabetes, a prevalence of 3.9 (95\% CI $3.7,4.1)$ per 1,000 deliveries. Descriptive statistics for pregnancies affected by pre-existing diabetes are shown in ESM Tables 1 and 2. Of these, 53\% involved male fetuses, $41 \%$ were primiparous, and $94 \%$ of the women were white. The median maternal age was 30 years (interquartile range [IQR] 25-34), and the median BMI was $27 \mathrm{~kg} / \mathrm{m}^{2}$ (IQR 24-32). A quarter (24\%) of women were recorded as smoking during pregnancy, and $32 \%$ as taking folic acid before pregnancy. Type 1 diabetes was recorded in $78 \%$ of the women, with the remaining $22 \%$ having type 2 . The median periconception and third-trimester $\mathrm{HbA}_{1 \mathrm{c}}$ concentrations were $62 \mathrm{mmol} / \mathrm{mol}$ (IQR 51-76) $(7.8 \%, \mathrm{IQR}=6.8-9.1)$ and $50 \mathrm{mmol} / \mathrm{mol}$ (IQR 43-58) $(6.7 \%, \mathrm{IQR}=6.1-7.5)$, respectively. The median gestational age at delivery was 37 weeks (IQR 36-38), and 38\% were delivered preterm ( $<37$ weeks).

Maternal pre-existing diabetes and the risks of fetal and infant death Forty-six fetal deaths (including five late miscarriages,
38 antepartum stillbirths and three intrapartum stillbirths) and ten infant deaths (including six neonatal deaths and four postneonatal deaths) were observed in women with preexisting diabetes. The prevalence of fetal death in women with pre-existing diabetes was 29.7 (95\% CI 21.8, 39.4) per 1,000 deliveries, over four times greater than in those without (RR 4.56 [95\% CI 3.42, 6.07], $p<0.0001$ ) (Table 1). The prevalence of fetal death was not significantly different between women with type 1 diabetes ( 28.2 [95\% CI 19.6, 39.2] per 1,000 deliveries) and women with type 2 diabetes (35.1 [95\% CI $18.3,60.5]$ per 1,000 deliveries) $(p=0.51)$. Significantly increased risks were observed for both antepartum stillbirths (RR 6.10 [95\% CI 4.44, 8.38], $p<0.0001$ ) and intrapartum stillbirths (RR 3.97 [95\% CI 1.27, 12.41], $p=0.042$ ). The estimated RR for a preterm fetal loss (RR 4.95 [95\% CI 3.59, 6.82], $p<0.0001$ ) was almost identical with that for a term stillbirth (RR 5.05 [95\% CI 2.62, 9.71], $p<0.0001$ ), although the RR for a late miscarriage was significantly smaller (RR 1.61 [95\% CI $0.67,3.86], p=0.25$ ) (Table 2). The prevalence of infant death in women with

Table 1 RR of a fetal or infant death (in normally formed singleton offspring) associated with maternal pre-existing diabetes in the North of England during 1996-2008

\begin{tabular}{|c|c|c|c|c|c|c|}
\hline \multirow[t]{2}{*}{ Outcome } & \multicolumn{2}{|c|}{ Without pre-existing diabetes } & \multicolumn{2}{|c|}{ With pre-existing diabetes } & \multirow[t]{2}{*}{$\mathrm{RR}(95 \% \mathrm{CI})$} & \multirow[t]{2}{*}{$p$ value } \\
\hline & $\begin{array}{l}\text { Cases } \\
\left(n=395,844^{\mathrm{a}} /\right. \\
\left.393,262^{\mathrm{b}}\right)\end{array}$ & $\begin{array}{l}\text { Prevalence } \\
(95 \% \mathrm{CI}) \text { per } 1,000 \\
\text { deliveries }^{\mathrm{c}} / \text { live } \\
\text { births }^{\mathrm{d}}\end{array}$ & $\begin{array}{l}\text { Cases } \\
\left(n=1,548^{\mathrm{a}} /\right. \\
\left.1,502^{\mathrm{b}}\right)\end{array}$ & $\begin{array}{l}\text { Prevalence } \\
(95 \% \text { CI) per } 1,000 \\
\text { deliveries } \text { c }^{\mathrm{c}} \text { live } \\
\text { births }^{\mathrm{d}}\end{array}$ & & \\
\hline Fetal or infant death & 3,988 & $10.1(9.8,10.4)$ & 56 & $36.2(27.4,46.7)$ & $3.59(2.77,4.65)$ & $<0.0001$ \\
\hline Fetal death $^{\mathrm{e}}$ & 2,582 & $6.5(6.3,6.8)$ & 46 & $29.7(21.8,39.4)$ & $4.56(3.42,6.07)$ & $<0.0001$ \\
\hline Late miscarriage $^{\mathrm{f}}$ & 796 & $2.0(1.9,2.2)$ & 5 & $3.2(1.0,7.5)$ & $1.61(0.67,3.86)$ & $0.25^{\mathrm{g}}$ \\
\hline Stillbirth $^{\mathrm{h}}$ & 1,786 & $4.5(4.3,4.7)$ & 41 & $26.5(19.1,35.8)$ & $5.87(4.32,7.97)$ & $<0.0001$ \\
\hline Antepartum stillbirth ${ }^{\mathrm{i}}$ & 1,593 & $4.0(3.8,4.2)$ & 38 & $24.5(17.4,33.5)$ & $6.10(4.44,8.38)$ & $<0.0001$ \\
\hline Intrapartum stillbirth ${ }^{\mathrm{j}}$ & 193 & $0.5(0.4,0.6)$ & 3 & $1.9(0.4,5.7)$ & $3.97(1.27,12.41)$ & $0.042^{\mathrm{g}}$ \\
\hline Infant death ${ }^{\mathrm{k}}$ & 1,406 & $3.6(3.4,3.8)$ & 10 & $6.7(3.2,12.2)$ & $1.86(1.00,3.46)$ & 0.046 \\
\hline Neonatal death ${ }^{1}$ & 904 & $2.3(2.1,2.5)$ & 6 & $4.0(1.5,8.7)$ & $1.74(0.78,3.87)$ & $0.17^{\mathrm{g}}$ \\
\hline Postneonatal death ${ }^{\mathrm{m}}$ & 502 & $1.3(1.2,1.4)$ & 4 & $2.7(0.7,6.8)$ & $2.09(0.78,5.57)$ & $0.13^{\mathrm{g}}$ \\
\hline
\end{tabular}

${ }^{\mathrm{a}}$ Total singleton live births, stillbirths and late miscarriages

b Total singleton live births

${ }^{\mathrm{c}}$ The prevalence of fetal or infant death, and fetal death and all subsidiary outcomes of fetal death are presented per 1,000 deliveries

${ }^{\mathrm{d}}$ The prevalence of infant death and all subsidiary outcomes are presented per 1,000 live births

${ }^{\mathrm{e}}$ Late miscarriages and stillbirths

${ }^{\mathrm{f}}$ Spontaneous loss of a fetus at 20-23 completed weeks of gestation

${ }^{\mathrm{g}}$ Fisher's exact test

${ }^{\mathrm{h}}$ Deliveries of a fetus showing no signs of life at 24 or more completed weeks of gestation

${ }^{\text {i }}$ Stillbirths where the fetus died before the onset of labour

${ }^{\mathrm{j}}$ Stillbirths where the fetus died after the onset of labour

${ }^{\mathrm{k}}$ Neonatal deaths and postneonatal deaths

${ }^{1}$ Death, after live birth, within the first 28 days of life

${ }^{\mathrm{m}}$ Death, after live birth, of an infant aged 28 days or more, but less than 1 year 
Table 2 Absolute and relative risks of a fetal death (in normally formed singleton offspring) associated with maternal pre-existing diabetes, by gestational age

\begin{tabular}{|c|c|c|c|c|c|c|c|c|c|c|}
\hline \multirow[t]{3}{*}{$\begin{array}{l}\text { Gestational } \\
\text { age (weeks) }\end{array}$} & \multirow{2}{*}{\multicolumn{2}{|c|}{ Fetal deaths }} & \multirow{2}{*}{\multicolumn{2}{|c|}{ Total deliveries }} & \multirow{2}{*}{\multicolumn{2}{|c|}{$\begin{array}{l}\text { Ongoing } \\
\text { pregnancies }\end{array}$}} & \multicolumn{3}{|c|}{ Risk during given gestational age $(95 \% \mathrm{CI})$} & \multirow[t]{3}{*}{$\begin{array}{l}\text { Compared with } \\
\mathrm{RR} \text { at term }\end{array}$} \\
\hline & & & & & & & \multicolumn{2}{|c|}{ Absolute risk (per 1,000 ongoing pregnancies) } & \multirow[t]{2}{*}{$\mathrm{RR}$} & \\
\hline & With & Without & With & Without & With & Without & With & Without & & \\
\hline Preterm (20-36) & 37 & 1,913 & 585 & 34,618 & 1,548 & 395,844 & $23.9(16.9,32.8)$ & $4.8(4.6,5.1)$ & $4.95(3.59,6.82)$ & $0.98(0.47,2.04)$ \\
\hline $20-23$ & 5 & 796 & 6 & $796^{\mathrm{a}}$ & 1,548 & 395,844 & $3.2(1.0,7.5)$ & $2.0(1.9,2.2)$ & $1.61(0.67,3.86)$ & $0.32(0.11,0.95)$ \\
\hline $24-27$ & 10 & 413 & 15 & 4,828 & 1,542 & 395,048 & $6.5(3.1,11.9)$ & $1.0(0.9,1.2)$ & $6.20(3.32,11.59)$ & $1.23(0.50,3.05)$ \\
\hline $28-36$ & 22 & 704 & 564 & 28,994 & 1,527 & 390,220 & $14.4(9.1,21.7)$ & $1.8(1.7,1.9)$ & $7.99(5.24,12.17)$ & $1.58(0.72,3.46)$ \\
\hline Term (37-41) & 9 & 669 & 963 & 361,226 & 963 & 361,226 & $9.3(4.3,17.7)$ & $1.9(1.7,2.0)$ & $5.05(2.62,9.71)$ & 1 (reference) \\
\hline Total & 46 & 2,582 & 1,548 & 395,844 & 1,548 & 395,844 & $29.7(21.8,39.4)$ & $6.5(6.3,6.8)$ & $4.56(3.42,6.07)$ & \\
\hline
\end{tabular}

Values are shown in women with and without pre-existing diabetes

${ }^{\text {a }}$ Bonellie et al [24] provide no estimate of the number of deliveries occurring during 20-23 weeks. This was approximated to be equal to the total number of fetal deaths during the same period

pre-existing diabetes was $6.7(3.2,12.2)$ per 1,000 live births, almost twice that in those without (RR 1.86 [95\% CI 1.00, 3.46], $p=0.046$ ) (Table 1). The prevalence of infant death was not significantly different between women with type 1 diabetes $(7.7$ [95\% CI 3.5, 14.5] per 1,000 live births) and women with type 2 diabetes $(3.0$ [95\% CI $0.8,16.8]$ per 1,000 deliveries $)(p=0.70)$.

Although the prevalence of fetal and infant death declined from $11.4(95 \%$ CI $10.8,12.0)$ per 1,000 deliveries in $1996-1999$ to $9.3(95 \%$ CI $8.8,9.9)$ per 1,000 deliveries in 2005-2008 $(p<0.0001)$, there was no change in the RR associated with diabetes (in 19961999: RR 4.5 [95\% CI 2.8, 7.0]; in 2005-2008: RR 4.3 $[95 \%$ CI $2.8,6.4])(p=0.95)$.

$H_{b A_{1 c}}$ and the odds of fetal and infant death Increasing periconception $\mathrm{HbA}_{1 \mathrm{c}}$ concentration above values of $49 \mathrm{mmol} / \mathrm{mol}(6.6 \%)$ (aOR per $\mathrm{mmol} / \mathrm{mol} 1.02$ [95\% CI $1.00,1.04], p=0.01$ ), prepregnancy retinopathy (aOR 2.05 [95\% CI 1.04, 4.05], $p=0.04$ ) and lack of prepregnancy folic acid consumption (aOR 2.52 [95\% CI 1.12, 5.65], $p=0.03$ ) were all independently associated with increased odds of fetal and infant death (ESM Table 3). Maternal smoking during pregnancy was also crudely associated with the risk of fetal and infant death (OR 1.91 [95\% CI 1.08, 3.36], $p=0.03$ ), but the association was not apparent after adjustment for periconception $\mathrm{HbA}_{1 \mathrm{c}}$ and folic acid consumption (aOR 1.54 [95\% CI 0.80, 2.94], $p=0.19)$. There was no evidence that the effects of periconception $\mathrm{HbA}_{1 \mathrm{c}}$, prepregnancy retinopathy or lack of prepregnancy folic acid consumption on the risk of fetal and infant death were different in women with type 2 diabetes compared with women with type 1 diabetes ( $p=0.85$, $p=0.24$, and $p=0.74$, respectively). In later pregnancy, increasing third-trimester $\mathrm{HbA}_{1 \mathrm{c}}$ concentration above values of
$43 \mathrm{mmol} / \mathrm{mol}(\mathrm{aOR} 1.06$ [95\% CI 1.03, 1.09], $p<0.001)$ and lack of prepregnancy folic acid consumption (aOR 3.01 [95\% CI 1.03, 8.79], $p=0.04$ ) were the only variables that were significantly associated with the odds of a late stillbirth or infant death (ESM Table 3).

When fetal and infant death were examined individually, increasing periconception $\mathrm{HbA}_{1 \mathrm{c}}$ concentration above values of $49 \mathrm{mmol} / \mathrm{mol}$ was the only variable that was significantly associated with either fetal death (OR 1.02 [95\% CI 1.01, 1.04], $p=0.01$ ) or infant death (OR 1.03 [95\% CI 1.00, 1.06], $p=0.01$ ). The association between periconception $\mathrm{HbA}_{1 \mathrm{c}}$ and the odds of fetal death followed a J-shaped pattern (Fig. 2), although the inverse association for values below $49 \mathrm{mmol} / \mathrm{mol}$ was not statistically significant (OR 0.95 [95\% CI $0.86,1.05]$, $p=0.31$ ).

The estimated absolute risks of fetal death, stillbirth, late stillbirth and infant death (overall and by periconception and third-trimester $\mathrm{HbA}_{1 \mathrm{c}}$ ) are reported in Table 3.

\section{Discussion}

Principal findings This large population-based study describes the association between pre-existing diabetes and measures of glycaemic control and the risks of fetal and infant death in normally formed singleton offspring. The prevalence of fetal death $(3 \%)$ was over four times greater in women with pre-existing diabetes, and the prevalence of infant death $(0.7 \%)$ was nearly doubled. There was no evidence that the RR of fetal and infant death associated with pre-existing diabetes decreased over time, nor that the RR of stillbirth varied by gestational age, although the RR was smaller for late miscarriages. 


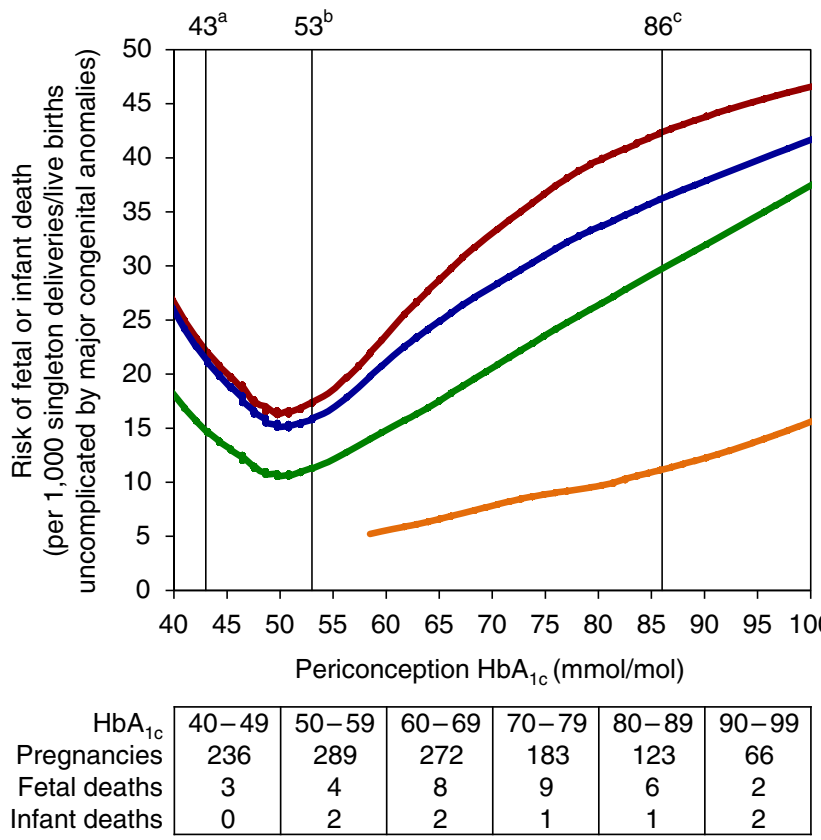

Fig. 2 Periconception $\mathrm{HbA}_{1 \mathrm{c}}$ and risk of fetal or infant death in women with pre-existing diabetes. Fetal deaths (red), stillbirths (blue) and late stillbirths (green) are deliveries of a fetus showing no signs of life at $\geq 20$ weeks of gestation, $\geq 24$ weeks of gestation, and $\geq 28$ weeks of gestation, respectively. Infant deaths (orange) are deaths, after live birth, within the first year of life. ${ }^{\mathrm{a}} \mathrm{A}$ prepregnancy $\mathrm{HbA}_{1 \mathrm{c}}$ target of $\leq 43 \mathrm{mmol} /$ mol is recommended by NICE: 'If it is safely achievable, women with diabetes who are planning to become pregnant should aim to maintain their $\mathrm{HbA}_{1 \mathrm{c}}$ below $6.1 \%$ [19]. ${ }^{\mathrm{b}} \mathrm{A}$ prepregnancy $\mathrm{HbA}_{1 \mathrm{c}}$ target of $\leq 53 \mathrm{mmol} / \mathrm{mol}$ is recommended by the ADA: 'A1C levels should be as close to normal as possible $(<7 \%)$ in an individual patient before conception is attempted.' [20]. ' NICE advises that women with a prepregnancy $\mathrm{HbA}_{1 \mathrm{c}}$ above $86 \mathrm{mmol} / \mathrm{mol}$ should be advised to avoid pregnancy: 'Women with diabetes whose $\mathrm{HbA}_{1 \mathrm{c}}$ is above $10 \%$ should be strongly advised to avoid pregnancy.' [19]. To convert values for $\mathrm{HbA}_{1 \mathrm{c}}$ in $\mathrm{mmol} /$ mol into \%, divide by 10.929 and add 2.15 , or use the conversion calculator at www.HbA1c.nu/eng/

Among women with pre-existing diabetes, increasing periconception $\mathrm{HbA}_{1 \mathrm{c}}$ concentration (for values above $49 \mathrm{mmol} / \mathrm{mol}$ ), history of retinopathy and lack of prepregnancy folic acid consumption were all associated with increased odds of fetal and infant death. Periconception $\mathrm{HbA}_{1 \mathrm{c}}$ concentration was also associated with increased odds of fetal and infant death individually, with each $1 \mathrm{mmol} / \mathrm{mol}$ increase (above $49 \mathrm{mmol} / \mathrm{mol}$ ) conferring a $2 \%$ and $3 \%$ relative increase, respectively. The association between $\mathrm{HbA}_{1 \mathrm{c}}$ and the odds of fetal death appeared to follow a J-shaped pattern.

There was no difference in the risk of fetal and/or infant death in women with type 1 diabetes compared with those with type 2 , nor was there any evidence that the associations with $\mathrm{HbA}_{1 \mathrm{c}}$ concentration, folic acid consumption, or history of retinopathy were different between types.

Strengths and limitations This study, describing one of the largest obstetric cohorts of women with pre-existing diabetes, benefits from the North of England's long history of collaboration between maternity and neonatal services, which created and maintains several complementary population-based registers. Detailed information was collected prospectively on a range of clinical and sociodemographic variables, including multiple measures of $\mathrm{HbA}_{1 \mathrm{c}}$. All late miscarriages, stillbirths and infant deaths in the region, regardless of whether they occurred in women with diabetes, were obtained from an established register of fetal and infant mortality, minimising the risk of bias from disparities in ascertainment. By excluding all cases of major congenital anomaly derived from an independent and long-standing population-based register (which should again be robust to disparities in ascertainment), this study is novel in describing the associations in normally formed offspring. The results are likely to be generalisable to any predominately white population with similar standards of periconception and perinatal care.

Several limitations result from low statistical power. Only six neonatal deaths, four postneonatal deaths and three intrapartum stillbirths were identified, preventing these events from being analysed with precision. For most analyses, fetal and infant deaths were combined, despite likely differences in aetiology [23]. Owing to instability at the tails of our LOWESS models, we only report absolute risks for the middle $90 \%$ of $\mathrm{HbA}_{1 \mathrm{c}}$ concentrations. The primary multivariate analyses had adequate power $(\beta=0.8)$ to detect a 'medium effect' (Cohen's $d \leq 0.5$, equivalent to an OR of $\geq 2.47$ ) for any variable with a baseline exposure probability of $14-65 \%$. Weaker associations, or associations in exposures outside this range, may therefore have been missed.

Our LOWESS models, unlike our regression models, made no account of the non-independence of repeat pregnancies in the same woman, introducing a potential source of error. For each regression model, however, the addition of the betweenmother intercept did not significantly improve the model and only engendered negligible changes in the other coefficients, suggesting that any bias is likely to be trivial.

Preconception $\mathrm{HbA}_{1 \mathrm{c}}$ concentrations were missing for half of the cohort, reflecting low attendance for preconception care. We therefore used a composite measure of periconception $\mathrm{HbA}_{1 \mathrm{c}}$ as a proxy for preconception $\mathrm{HbA}_{1 \mathrm{c}}$. Although firsttrimester values correlate highly with preconception, this may have introduced random error. $\mathrm{HbA}_{1 \mathrm{c}}$ itself is an imperfect measure of glycaemic control, as it provides no information on glycaemic excursions or hypoglycaemic episodes [27], which may be important in the aetiopathology of fetal and/or infant death [28]. Continuous glucose monitoring provides a more complete record of day to day glycaemic control, but is not routinely used in the UK. No information was recorded on pharmacological treatments, so we could not explore their possible contribution. Since the PMMS does not collect information on miscarriages before 20 weeks, we were not able to examine the RR of earlier fetal losses, the risks of which may 


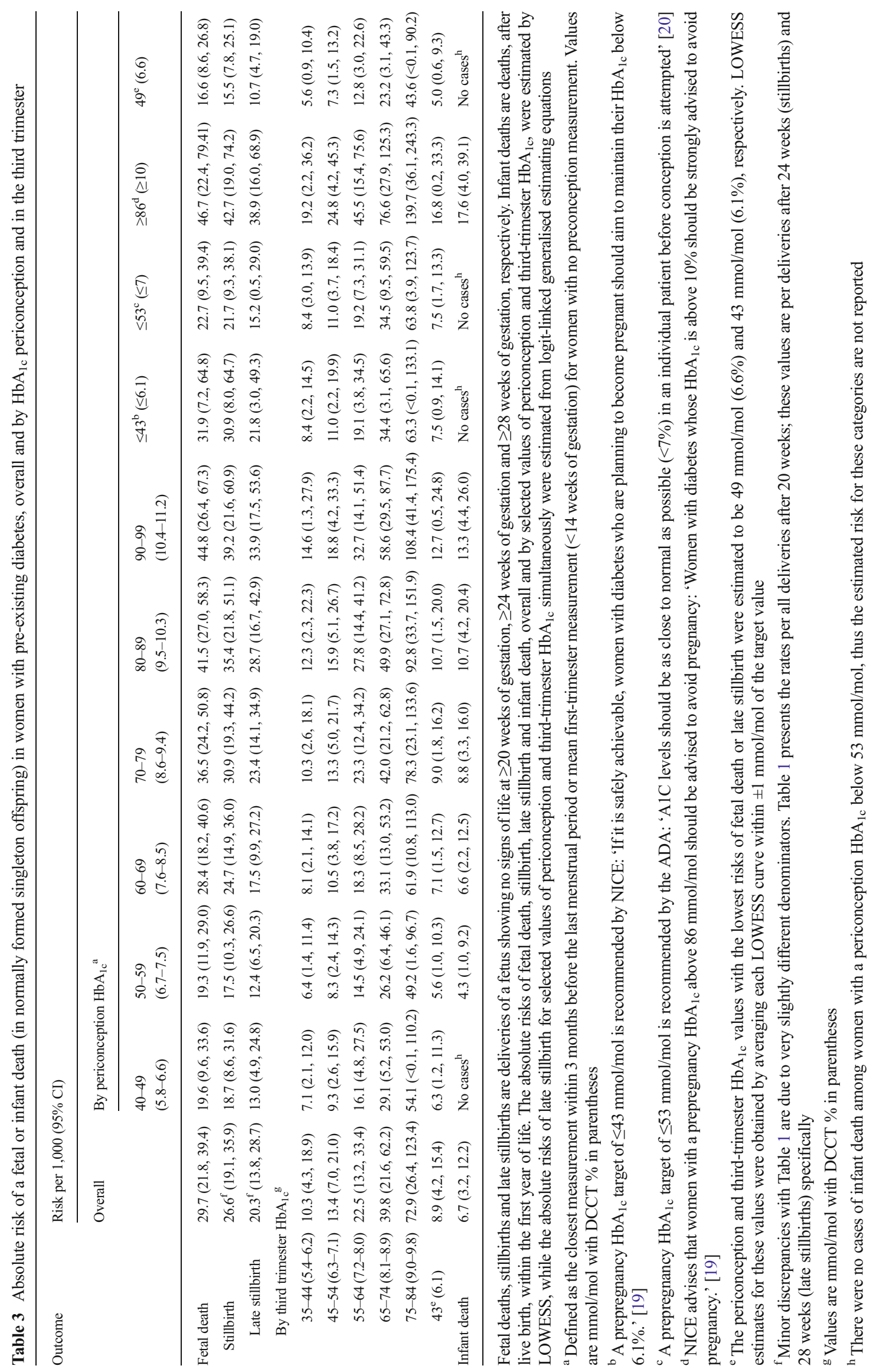


also be raised in women with diabetes. Finally, although the PMMS records cause of death, over half of all deaths were attributed simply to 'maternal disorder', preventing us from exploring whether diabetes was associated with any particular cause.

Comparison with other studies Flenady et al [5] conducted an abridged meta-analysis, including just four studies, which estimated that the RR of stillbirth was around three times higher in women with diabetes than in those without (OR 2.90 [95\% CI 2.05, 4.09]). This is smaller than our estimates for both fetal death (OR 4.56 [95\% CI 3.42, 6.07]) and stillbirth (OR 5.87 [95\% CI 4.32, 7.97]). The largest study to examine the RR of fetal death is the analysis by Mondestin et al [9] of data from the US natality and mortality surveys during 1995-1997. Describing 271,691 pregnancies complicated by diabetes and excluding births with recorded congenital anomalies, they reported an RR for fetal death of $2.0(95 \%$ CI 1.8, 2.2), less than half our estimate. This may be because they did not distinguish between pre-existing and gestational diabetes or may reflect ascertainment deficiencies inherent in using birth certificate data. Recent data from Ontario describing deliveries from 2005-2006 showed an even smaller RR for stillbirth of $1.53(95 \%$ CI $0.88,2.63)$ for pre-existing diabetes, although they also found an implausible protective effect for gestational diabetes (RR 0.33 [95\% CI 0.12, 0.71]) [10]. In a large cohort from Australia including 433,379 deliveries from 1998-2002, Mohsin et al [11] reported a similarly small RR of 1.87 (95\% CI 1.01, 3.48), although it was not indicated how diabetes was defined or ascertained.

There is more agreement between studies from Northern Europe, which typically report RRs of four to five times for stillbirth and two to four times for neonatal/infant death. In a large study of women with type 1 diabetes from Sweden during 1991-2003, Persson et al reported ORs of 4.04 (95\% CI 3.02, 5.40) and 3.08 (95\% CI 2.02, 4.70) for late stillbirth and neonatal death, respectively [12], while Jensen et al's study from Denmark during 1993-1999 reported corresponding RRs of 4.72 (95\% CI 3.18, 7.01) and 3.40 (95\% CI 1.91, 6.07) [13]. Eidem et al's study from Norway during 19852004 reported smaller, though not statistically inconsistent, ORs of 3.6 (95\% CI 2.5, 5.3) and 1.9 (95\% CI 1.1, 3.2), respectively [14]. Four studies from the UK reported strikingly similar results, possibly reflecting the increased homogeneity of care [15-18]. The four RR estimates for stillbirth ranged between 4.39 (95\% CI 2.22, 8.64) and 4.7 (95\% CI 3.7, 6.0) [15-18], while the two estimates of neonatal death were 2.4 $(95 \%$ CI 1.4, 4.1) and 2.6 (95\% CI 1.7, 3.9) [15, 17].

Eidem et al [14] and dos Santos Silva et al [15] examined whether the RR of stillbirth associated with diabetes varied by gestational age, both reporting that the effect was confined to term deliveries. In contrast, we found the RR of stillbirth was uniformly raised for all gestational ages. This discrepancy is due to different methodological approaches. Eidem et al and dos Santos Silva et al used the traditional method of calculating stillbirth rate per deliveries in that period, an approach that is highly susceptible to confounding by differences in gestational age distribution. The rate of induced preterm birth is considerably higher among women with diabetes than among those without [29]. This shift in the denominator produces an artefactually smaller stillbirth rate during preterm (and a larger one during term). By offsetting against the total population of fetuses at risk of fetal death at a particular gestational age, rather than simply the sample of deliveries at that gestational age, our findings are robust to this problem [23].

Few studies have described the continuous association between $\mathrm{HbA}_{1 \mathrm{c}}$ and the risk of fetal and/or infant death. Using LOWESS, Nielsen et al demonstrated an approximately linear association between increasing first-trimester $\mathrm{HbA}_{1 \mathrm{c}}$ above $53 \mathrm{mmol} / \mathrm{mol}(7 \%)$ and the risk of 'adverse outcome', although this included congenital anomalies and elective terminations [30]. In women with type 1 diabetes, Jensen et al found that the RR of perinatal mortality increased steadily from $2.8(95 \% \mathrm{CI} 1.3,6.1)$ to $7.3(95 \% \mathrm{CI} 2.5,19.8)$ as periconception $\mathrm{HbA}_{1 \mathrm{c}}$ increased from $<52 \mathrm{mmol} / \mathrm{mol}$ $(<6.9 \%)$ to $>90 \mathrm{mmol} / \mathrm{mol}(>10.4 \%)$, respectively [31]. Neither Nielsen et al nor Jensen et al specifically examined whether low values of $\mathrm{HbA}_{1 \mathrm{c}}$ were potentially harmful, although Nielsen et al's LOWESS curve showed evidence of the same J-shape as observed in our study.

The association between retinopathy, or any microvascular complication, and the risk of fetal or infant death in women with diabetes has not been well described. Contrasting with the current study, Jensen et al found no significant difference $(p=0.58)$ in the rate of 'serious adverse outcome' (perinatal death and/or congenital anomaly) between women with and without retinopathy [13], although the proportion diagnosed with retinopathy was considerably smaller than in our cohort. In a previous study in women with diabetes in the North of England, nephropathy, but not retinopathy, was associated with an increased risk of congenital anomalies [2].

To our knowledge, this is the first study to explore the association between prepregnancy folic acid and the risk of fetal and infant death in women with diabetes. However, in a mixed population from England, during 2009-2011, Gardosi et al also identified a lower risk of stillbirth among women who had taken antenatal folic acid [32].

Implications and conclusions In England, the National Institute for Health and Care Excellence (NICE) recommends that women with pre-existing diabetes aim for a preconception $\mathrm{HbA}_{1 \mathrm{c}}$ below $43 \mathrm{mmol} / \mathrm{mol}(6.1 \%)$ [19]. The ADA suggest $53 \mathrm{mmol} / \mathrm{mol}(7 \%)$ [20]. Our results strongly support the attainment and maintenance of good glycaemic control before and throughout pregnancy. If the average periconception $\mathrm{HbA}_{1 \mathrm{c}}$ had been $53 \mathrm{mmol} / \mathrm{mol}$ (the ADA target), rather than 
$62 \mathrm{mmol} / \mathrm{mol}$ (the population median), then our estimates suggest that the prevalence of fetal and infant death would have been $38 \%$ lower. However, we found evidence of a $\mathrm{J}$ shaped association between $\mathrm{HbA}_{1 \mathrm{c}}$ concentration and the risk of fetal death. Although it is implausible that euglycaemic levels of $\mathrm{HbA}_{1 \mathrm{c}}$ are harmful, it is possible that hypoglycaemic episodes, which are more common in women with diabetes and low $\mathrm{HbA}_{1 \mathrm{c}}$ [33], may be [28]. At the least, our results show that for fetal deaths, as for congenital anomalies [2], there appears to be no substantive benefit of achieving periconception levels below the ADA target. At the other extreme, NICE discourages pregnancy when the preconception $\mathrm{HbA}_{1 \mathrm{c}}$ is above $86 \mathrm{mmol} / \mathrm{mol}(10 \%)$ [19]. In demonstrating a clear continuum in risk above $53 \mathrm{mmol} / \mathrm{mol}$, our results provide no evidence for this specific threshold.

Even in women with optimal periconception $\mathrm{HbA}_{1 \mathrm{c}}$ concentration (with values of $49 \mathrm{mmol} / \mathrm{mol}$ ), we estimated the risk of fetal death to be over twice as high as in women without diabetes (16.6 [95\% CI 8.6, 26.8] vs 6.5 [95\% CI 6.3, 6.8] per 1,000 deliveries). This may reflect the limitations of $\mathrm{HbA}_{1 \mathrm{c}}$ as a marker of glycaemic control, or it may suggest that other risk factors are operating in women with diabetes.

The rate of fetal and infant death was over two times higher among women who did not take prepregnancy folic acid supplements. Women with pre-existing diabetes are advised to take high doses ( $5 \mathrm{mg}$ /day) of folic acid specifically 'to reduce the risk of having a baby with a neural tube defect' [19]. Our results suggest there may be additional benefits for normally formed offspring, although folic acid use may also simply indicate better preparation for pregnancy.

History of retinopathy was associated with a doubling of the risk of fetal and infant death. It is possible that retinopathy indicates a prolonged history of poor glycaemic control that is not adequately described by $\mathrm{HbA}_{1 \mathrm{c}}$, or it may signify wider microvascular deficiencies that might impair placental development. These women may warrant additional support when planning their pregnancy.

Over 20 years after the St Vincent Declaration, we found that the excess risk of fetal and infant death in women with diabetes has remained stubbornly persistent. In the North of England, fewer than half of women with pre-existing diabetes attend preconception care, with the proportion declining over time [34]. To achieve any reduction in the RR of stillbirth and infant death in women with pre-existing diabetes, the barriers to uptake of preconception care and adequate preparation for pregnancy must be urgently understood and addressed.

Acknowledgements We are grateful to all the district convenors and coordinators in the North of England for their continued collaboration and support of the NorDIP, PMMS and NorCAS. We also thank the staff at the Public Health England: Regional Maternity Survey Office, Newcastle upon Tyne, UK, for their help in data tracing and checking.
Funding This study was part funded by Diabetes UK (BDA number 10/0004019). The NorDIP, PMMS and NorCAS are funded by Public Health England.

Duality of interest The authors declare that there is no duality of interest associated with this manuscript.

Contribution statement All authors declare that they read and approved the final version of the manuscript before submission. RB conceived the project and, with JR and SVG, designed the study. PWGT performed the data analysis and drafted the manuscript. RWB was involved in the acquisition of the data. All authors were involved in the interpretation of the data and critically reviewed the manuscript. PWGT had full access to all the data and had final responsibility for the decision to submit for publication.

\section{References}

1. Glinianaia SV, Tennant PWG, Bilous RW, Rankin J, Bell R (2012) $\mathrm{HbAlc}$ and birthweight in women with pre-conception type 1 and type 2 diabetes: a population-based cohort study. Diabetologia 55: 3193-3203

2. Bell R, Glinianaia SV, Tennant PWG, Bilous RW, Rankin J (2012) Peri-conception hyperglycaemia and nephropathy are associated with risk of congenital anomaly in women with pre-existing diabetes: a population-based cohort study. Diabetologia 55:936-947

3. Ehrenberg HM, Durnwald CP, Catalano P, Mercer BM (2004) The influence of obesity and diabetes on the risk of cesarean delivery. Am J Obstet Gynecol 191:969-974

4. Pedersen JR, Brandstrup E (1956) Foetal mortality in pregnant diabetics; strict control of diabetes with conservative obstetric management. Lancet 270:607

5. Flenady V, Koopmans L, Middleton P et al (2011) Major risk factors for stillbirth in high-income countries: a systematic review and metaanalysis. Lancet 377:1331-1340

6. Wahabi H, Alzeidan R, Bawazeer G, Alansari L, Esmaeil S (2010) Preconception care for diabetic women for improving maternal and fetal outcomes: a systematic review and meta-analysis. BMC Pregnancy Childbirth 10:63

7. McElvy SS, Miodovnik M, Rosenn B et al (2000) A focused preconceptional and early pregnancy program in women with type 1 diabetes reduces perinatal mortality and malformation rates to general population levels. J Matern Fetal Med 9:14-20

8. (1990) Diabetes care and research in Europe: the Saint Vincent Declaration. Diabet Med 7:360

9. Mondestin MA, Ananth CV, Smulian JC, Vintzileos AM (2002) Birth weight and fetal death in the United States: the effect of maternal diabetes during pregnancy. Am J Obstet Gynecol 187: 922-926

10. Peticca P, Keely EJ, Walker MC, Yang Q, Bottomley J (2009) Pregnancy outcomes in diabetes subtypes: how do they compare? A province-based study of Ontario, 2005-2006. J Obstet Gynaecol Can 31:487-496

11. Mohsin M, Bauman AE, Jalaludin B (2006) The influence of antenatal and maternal factors on stillbirths and neonatal deaths in New South Wales, Australia. J Biosoc Sci 38:643-657

12. Persson M, Norman M, Hanson U (2009) Obstetric and perinatal outcomes in type 1 diabetic pregnancies: a large, population-based study. Diabetes Care 32:2005-2009

13. Jensen DM, Damm P, Moelsted-Pedersen L et al (2004) Outcomes in type 1 diabetic pregnancies: a nationwide, population-based study. Diabetes Care 27:2819-2823 
14. Eidem I, Vangen S, Hanssen KF et al (2011) Perinatal and infant mortality in term and preterm births among women with type 1 diabetes. Diabetologia 54:2771-2778

15. dos Santos Silva I, Higgins C, Swerdlow AJ et al (2005) Birthweight and other pregnancy outcomes in a cohort of women with pregestational insulin-treated diabetes mellitus, Scotland, 1979-95. Diabet Med 22:440-447

16. Casson IF, Clarke CA, Howard CV et al (1997) Outcomes of pregnancy in insulin dependent diabetic women: results of a five year population cohort study. BMJ 315:275-278

17. Macintosh MC, Fleming KM, Bailey JA et al (2006) Perinatal mortality and congenital anomalies in babies of women with type 1 or type 2 diabetes in England, Wales, and Northern Ireland: population based study. BMJ 333:177

18. Wood SL, Jick H, Sauve R (2003) The risk of stillbirth in pregnancies before and after the onset of diabetes. Diabet Med 20:703-707

19. National Institute for Health and Clinical Excellence (2008) Diabetes in pregnancy: management of diabetes and its complications from pre-conception to the postnatal period. NICE Clinical Guideline 63. National Institute for Health and Clinical Excellence, London, UK. http://guidance.nice.org.uk/CG63. Accessed 10 May 2013

20. American Diabetes Association (2013) Executive summary: standards of medical care in diabetes-2013. Diabetes Care 36:S4-S10

21. Tennant PWG, Pearce MS, Bythell M, Rankin J (2010) 20-year survival of children born with congenital anomalies: a populationbased study. Lancet 375:649-656

22. Northern Regional Health Authority Coordinating Group (1984) Perinatal mortality: a continuing collaborative regional survey. $\mathrm{Br}$ Med J (Clin Res Ed) 288:1717-1720

23. Kramer MS, Liu S, Luo Z et al (2002) Analysis of perinatal mortality and its components: time for a change? Am J Epidemiol 156:493-497
24. Bonellie S, Chalmers J, Gray R, Greer I, Jarvis S, Williams C (2008) Centile charts for birthweight for gestational age for Scottish singleton births. BMC Pregnancy Childbirth 8:5

25. Cleveland WS (1979) Robust locally weighted regression and smoothing scatterplots. J Am Stat Assoc 74:829-836

26. Oehlert GW (1992) A note on the delta method. Am Stat 46:27-29

27. Nalysnyk L, Hernandez-Medina M, Krishnarajah G (2010) Glycaemic variability and complications in patients with diabetes mellitus: evidence from a systematic review of the literature. Diabetes Obes Metab 12:288-298

28. Abell DA, Beischer NA (1975) Evaluation of the three-hour oral glucose tolerance test in detection of significant hyperglycemia and hypoglycemia in pregnancy. Diabetes 24:874-880

29. Melamed N, Chen R, Soiberman U, Ben-Haroush A, Hod M, Yogev Y (2008) Spontaneous and indicated preterm delivery in pregestational diabetes mellitus: etiology and risk factors. Arch Gynecol Obstet 278:129-134

30. Nielsen GL, Moller M, Sorensen HT (2006) HbA1c in early diabetic pregnancy and pregnancy outcomes: a Danish population-based cohort study of 573 pregnancies in women with type 1 diabetes. Diabetes Care 29:2612-2616

31. Jensen DM, Korsholm L, Ovesen P et al (2009) Peri-conceptional $\mathrm{A} 1 \mathrm{C}$ and risk of serious adverse pregnancy outcome in 933 women with type 1 diabetes. Diabetes Care 32:1046-1048

32. Gardosi J, Madurasinghe V, Williams M, Malik A, Francis A (2013) Maternal and fetal risk factors for stillbirth: population based study. BMJ 346:f108

33. Callaghan BC, Little AA, Feldman EL, Hughes RA (2012) Enhanced glucose control for preventing and treating diabetic neuropathy. Cochrane Database Syst Rev 6, CD007543

34. Glinianaia SV, Crowder D, Bell R (2013) [Abstract] Trends and determinants of preparation for pregnancy: regional populationbased cohort study, 1996-2010. Diabet Med 30:169-170 